[DOI: 10.24214/jecet.A.9.1.09400.]

Jaurnal of Environmental Science, Computer Science and Engineering \& Technology

An International Peer Review E-3 Journal of Sciences and Technology

Available online at www.jecet.org

Section A: Environmental Science

Research Article

\title{
Extraction and Characterisation of Wax from Cassava Bagasse by FT-IR, UV-Vis and SEM
}

\author{
*Abiaziem Chioma V. and Adebisi Evelyn U. \\ Department of Science Laboratory Technology, the Federal Polytechnic Ilaro, P.M.B. 50, \\ Ogun State, Nigeria.
}

Received: 16 November 2019; Revised: 06 December 2019; Accepted: 16 December 2019

\begin{abstract}
Cassava bagasse is one of the abounding garbage procured from the extraction of cassava. Extraction of products of high value from agricultural wastes is a crucial constituent for sustainable techno economic development. In this study, extraction and characterisation of wax from cassava bagasse was carried out. About $9.86 \%(\mathrm{w} / \mathrm{w})$ of crude cassava wax was obtained from the cassava bagasse using the mixture of benzene and methanol (mass ratio of 2:1) as the extraction reagents. The wax extracted was characterised using fourier transform infra-red spectroscopy (FTIR), ultraviolet visible spectroscopy (UV-Vis) and scanning electron microscopy (SEM). The physicochemical properties were studied: melting point, saponification value, acid value, ester value and iodine value. Results of fourier transform infra-red spectroscopy revealed prominent peaks at $2911 \mathrm{~cm}^{-1}(\mathrm{CH}), 1464 \mathrm{~cm}^{-1}\left(\mathrm{CH}_{2}\right), 1028 \mathrm{~cm}^{-}$ ${ }^{1}(-\mathrm{C}-\mathrm{O}), 1717 \mathrm{~cm}^{-1}(-\mathrm{CHO})$ and $3382 \mathrm{~cm}^{-1}(\mathrm{OH})$ illustrating the presence of alkanes, ketones, aldehyde and alcohol, respectively. The ultraviolet qualitative analysis displayed the existence of conjugated dienes at $245 \mathrm{~nm}$. The dewaxed sample showed a rough, cracked and individualised surface indicating the removal of wax. In addition, the physicochemical properties of the wax which comprises of melting point, saponification value, acid value, ester value and iodine value were $62.5^{\circ} \mathrm{C}, 275,29.15$, $245.85,14.66$ and $22.54 \mathrm{mg} / \mathrm{KOH} / \mathrm{g}$, respectively. Thus, cassava bagasse wax has relevance for various industrial applications in food, pharmaceutical, cosmetics, medicine and several biological importance.
\end{abstract}

Keywords: Extraction, cassava bagasse, characterisation, agricultural wastes, dewax 


\section{INTRODUCTION}

Cassava is the third-largest source of food carbohydrates in the tropics, after rice and maize ${ }^{1}$. It is a vital staple food in the developing world, providing an essential diet for over half a billion people and one of the most drought-tolerant crops, capable of growing on marginal soils ${ }^{2}$. Nigeria is the world's largest producer of cassava and its bagasse is one of the ample remnant attained from the extraction of cassava. Extraction of products of high value from agricultural wastes is an essential component for sustainable techno economic ${ }^{3}$.

Cassava bagasse wax was extracted using soxhlet extraction method with a mixture of benzene and methanol. The wax portion finds its applications in textiles, paper, pharmaceutical and cosmetic industries ${ }^{4}$. The present study aimed at adding value to cassava by using their bagasse as raw material to extract wax. This also proffers solution to the problem of haphazard disposal of bagasse of cassava, which creates nuisance in the environment. The utilization of cassava bagasse (agricultural wastes) into wax is considered a potent product for various industrial applications. Thus, cassava bagasse wax has many compounds of biological and industrial importance.

\section{MATERIALS AND METHODS}

Sample Collection: Cassava bagasse (agro-waste) was collected from a cassava processing factory in Ilaro, Ogun state, Nigeria. The sample was washed to remove dirt and dried to a constant weight in a hot air oven at $80^{\circ} \mathrm{C}$ after which it was triturated in a mill into fine powder and stored in plastic containers.

Wax Extraction: Wax was extracted from cassava bagasse as reported by Anuj et al. ${ }^{5}$. The cassava bagasse powder was extracted using soxhlet extraction method with benzene and ethanol mixture of 2:1 $\mathrm{v} / \mathrm{v}$ for $8 \mathrm{~h}$ to remove wax. The solvent was evaporated using rotary evaporator (Buchi, Switzerland) and the residue primarily contained wax mixtures with some impurities. The residue was dissolved in isopropanol and was refluxed with charcoal for 1-2 $\mathrm{h}$ to remove any undesirable colour or pigments present. The extract was then filtered to remove the charcoal and evaporated at $60^{\circ} \mathrm{C}$ to obtain crude wax.

\section{Physicochemical Analysis}

Acid Value: $5.0 \mathrm{~g}$ of wax was weighed into a dry conical flask, $25 \mathrm{ml}$ of absolute ethanol and 2 drops of phenolphthalein indicator were added to the mixture. The mixture was heated with continuous shaking in water bath for $10 \mathrm{~min}$ and cooled. The cooled mixture was titrated against $0.1 \mathrm{~N} \mathrm{KOH}$ solution until pink colour appeared. The acid value was calculated

Saponification Value: $2 \mathrm{~g}$ of the wax sample was weighed into a $250 \mathrm{ml}$ conical flask and $25 \mathrm{ml}$ of alcoholic potassium iodide was dissolved in it. A reflux condenser was attached and the flask content was heated on a boiling hot water for 1 hour with occasional shaking, 3 drops of phenolphthalein indicator was added and then titrated with $0.5 \mathrm{~N} \mathrm{HCl}$. This was repeated for blank sample.

Iodine Value Determination: $2 \mathrm{~g}$ of the wax was weighed, $10 \mathrm{ml}$ of chloroform and 30ml of Hannus solution was added into a $250 \mathrm{ml}$ conical flask, the flask was sealed with parafilm and the solution was agitated for $30 \mathrm{~min}$. A mixture of $10 \mathrm{ml}$ of $15 \%$ potassium iodide and $10 \mathrm{ml}$ of distilled water was added. The iodine solution was titrated against $0.1 \mathrm{~N}$ sodium thiosulphate solution using starch as an indicator. This was repeated for blank.

Melting Point: The melting point of cassava peel wax was done according to the method adopted by Bekele et al. ${ }^{6}$. The wax was melted by warming it in a hot water bath and the melting point was 
determined by the capillary tube method or the drop point method. Melted wax was introduced in a 10 $\mathrm{cm}$ long and $2 \mathrm{~mm}$ internal diameter thin-wall hollow capillary tube, until reaching a height of about 1 $\mathrm{cm}$. After that, the capillary tube, containing the wax, was introduced into a bath of water that was slowly warmed at $1-2{ }^{\circ} \mathrm{C} / \mathrm{min}$; the temperature was studied with a thermometer (with an accuracy of $0.1{ }^{\circ} \mathrm{C}$ ) whose bulb had to be as close as possible to the beeswax column introduced in the capillary tube.

\section{Characterisation}

Fourier Transform Infrared Analysis: For the analysis, wax sample was placed on the diamond crystal and the ATR holder was screwed onto the sample to have a good contact with the crystal. The PerkinElmer spectrum 400 FT-IR spectrometer was set to scan 60 times at a resolution of $2.0 \mathrm{~cm}^{-1}$ over the wavelength range of $4000 \mathrm{~cm}^{-1}$ to $650 \mathrm{~cm}^{-1}$ against the transmittance. After every scan, the baseline was corrected using the background spectrum previously obtained from the blank.

UV-Vis Analysis: A known quantity of wax $(0.1 \% \mathrm{w} / \mathrm{v})$ was dissolved in hexane for spectroscopic measurement. The solvent was scanned across wavelength of 200 to $600 \mathrm{~nm}$ by using Helios $\alpha$ spectrophotometer (Thermo Electron Corporation, USA).

High Resolution Scanning Electron Microscopy (HR-SEM): The samples were prepared by coating with carbon to make SEM analysis conductive, HRSEM (AURIGA Field Emission High Resolution Scanning Electron Microscope) Zeiss, Germany, carbon evaporator was used for the coating process. In this research, AURIGA Field Emission High Resolution Scanning Electron Microscope was used to analyse the surface morphology of the raw, dewaxed sample.

\section{RESULTS AND DISCUSSION}

Yield of Cassava Bagasse Wax: The yield of wax from cassava bagasse was 9.86\%. This was similar to that reported by Abiaziem and Ojelade ${ }^{7}$, which was $8.51 \%$ and was high when compared to that reported by Mangesh et al. ${ }^{8}$ and Gaoxiang et al. ${ }^{9}$, which was found to be $0.95 \%$ and $1.2 \%$ (w/w). This could be as a result of the selective extractability of the main components in wax, a mixture with different polarities (mass ratio of benzene and methanol 2:1), as this mixture could efficiently extract both polar and nonpolar compounds and give a high wax yield from cassava bagasse.

Physicochemical Analysis: Table 1 shows the results of the physicochemical parameters of the wax extracted. In this present study, wax from cassava bagasse which is crude in nature showed a melting point of $62.5^{\circ} \mathrm{C}$, which was comparable to that reported by Gaoxiang et. al. ${ }^{9}$; Mangesh et al. ${ }^{8}$, which were $62.12^{\circ} \mathrm{C}$ and $62.39^{\circ} \mathrm{C}$, respectively.

Table 1: Physicochemical properties of extracted cassava bagasse wax

\begin{tabular}{ll}
\hline Physicochemical parameters & Cassava bagasse wax \\
\hline Colour & Pale brown \\
Acid value $(\mathrm{mg} / \mathrm{KOH} / \mathrm{g})$ & 29.15 \\
Saponification value $(\mathrm{mg} / \mathrm{KOH} / \mathrm{g})$ & 275 \\
Ester value $(\mathrm{mg} / \mathrm{KOH} / \mathrm{g})$ & 245.85 \\
Percentage yield $(\%)$ & 9.86 \\
Iodine value $(\mathrm{g} / 100)$ & 22.54 \\
Melting point $\left({ }^{\circ} \mathrm{C}\right)$ & 62.5 \\
\hline
\end{tabular}


However, it was found to be higher than that reported by ${ }^{8}$ which was $55-56^{\circ} \mathrm{C}$. The results of the acid value, saponification value, ester value and iodine value was found to be $29.15(\mathrm{mg} / \mathrm{KOH} / \mathrm{g})$, $275(\mathrm{mg} / \mathrm{KOH} / \mathrm{g}), 245.85(\mathrm{mg} / \mathrm{KOH} / \mathrm{g})$ and $22.54(\mathrm{mg} / \mathrm{KOH} / \mathrm{g})$, respectively.

FT-IR Analysis: Figure 1 presents the FT-IR spectra of wax from cassava bagasse sample which reveals the presence of many organic functional group present in the wax indicating their respective compounds. Comparison of the absorption frequency of various organic functional group revealed bands at $2911 \mathrm{~cm}^{-1}$ characteristic of $-\mathrm{CH}$ stretch and bend whereas bands at $1082 \mathrm{~cm}^{-1}$ and $1464 \mathrm{~cm}^{-1}$ signifies the present of $\mathrm{CH}_{2}$ and $\mathrm{CH}_{3}$ bands. Bands at $3382 \mathrm{~cm}^{-1}$ indicates the presence of $\mathrm{OH}$ group in the wax sample as a result of the sharp peak. Similarly, bands at $1717 \mathrm{~cm}^{-1}$ and $1732 \mathrm{~cm}^{-1}$ indicates the presence of carbonyl group. Similar results were observed in the characterization of sugarcane bagasse as reported by Mangesh et al. ${ }^{8}$. According to Gaoxiang $e t$ al. ${ }^{9}$, the FTIR characterisation of sugarcane bagasse revealed the presence of many functionalities such as alkanes, alcohol, fatty acids, aldehyde and small amount of lignin derivatives.

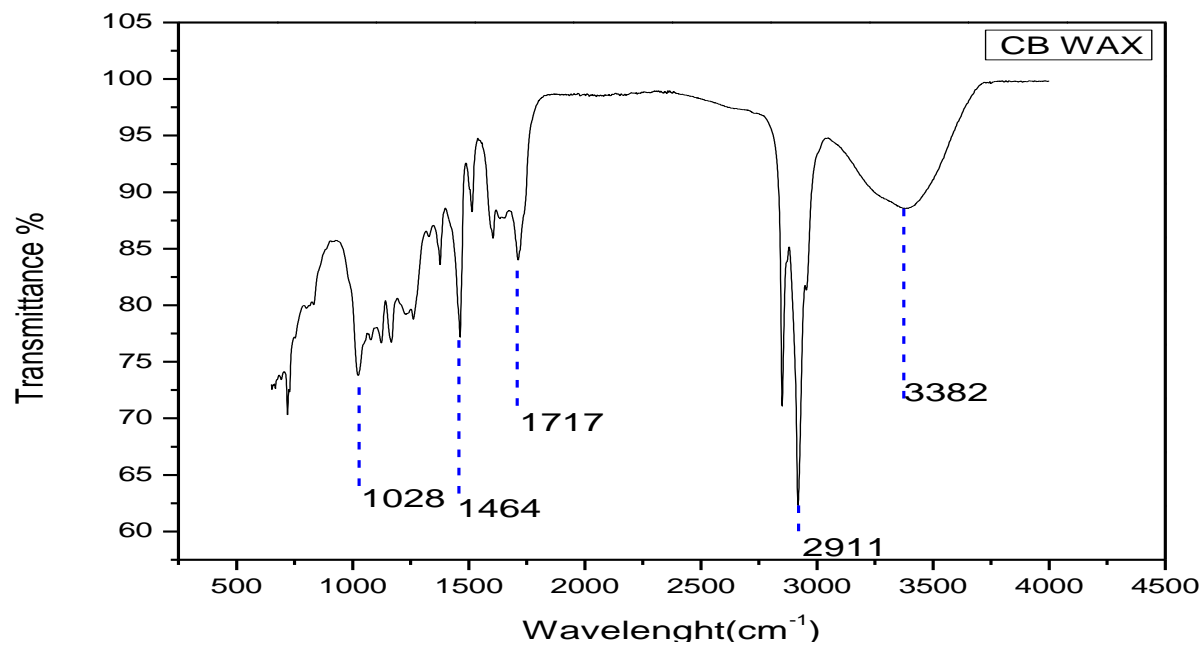

Figure 1: FT-IR spectra of crude wax from cassava bagasse

UV-Vis Analysis: Fatty acids, conjugated dienes, and hydroperoxide formed as a result of lipid oxidation absorbing UV light at about $230 \mathrm{~nm}$. In the UV region (100- $400 \mathrm{~nm}$ ), cassava bagasse wax in Figure 2 showed a maximum wavelength of absorption at $245 \mathrm{~nm}$, which is conjugated trienes. This result was similar to that reported by Mangesh et al. ${ }^{8}$, which showed peaks near 230 and $270 \mathrm{~nm}$ indicating the presence of conjugated dienes and trienes for sugarcane peel wax. The result was also in accordance with Athukoralaet al. ${ }^{10}$, where wax from (Linumusitatissium) straw showed similar pattern.

High Resolution Scanning Electron Microscopy (HR-SEM): The smooth surface of the untreated sample (raw) of the cassava bagasse in Fig. 3a was due to the presence of some non-fibrous components in the fibre surface such as lignin, hemicellulose, wax, pectin, oil etc. Figure 3b showed the surface morphology of dewaxed cassava peel, which appeared rough, with a decrease in size which may have ensued from the removal of lignin, hemicellulose and other non-cellulosic constituents showing a defibrillated fibrils ${ }^{11}$. 


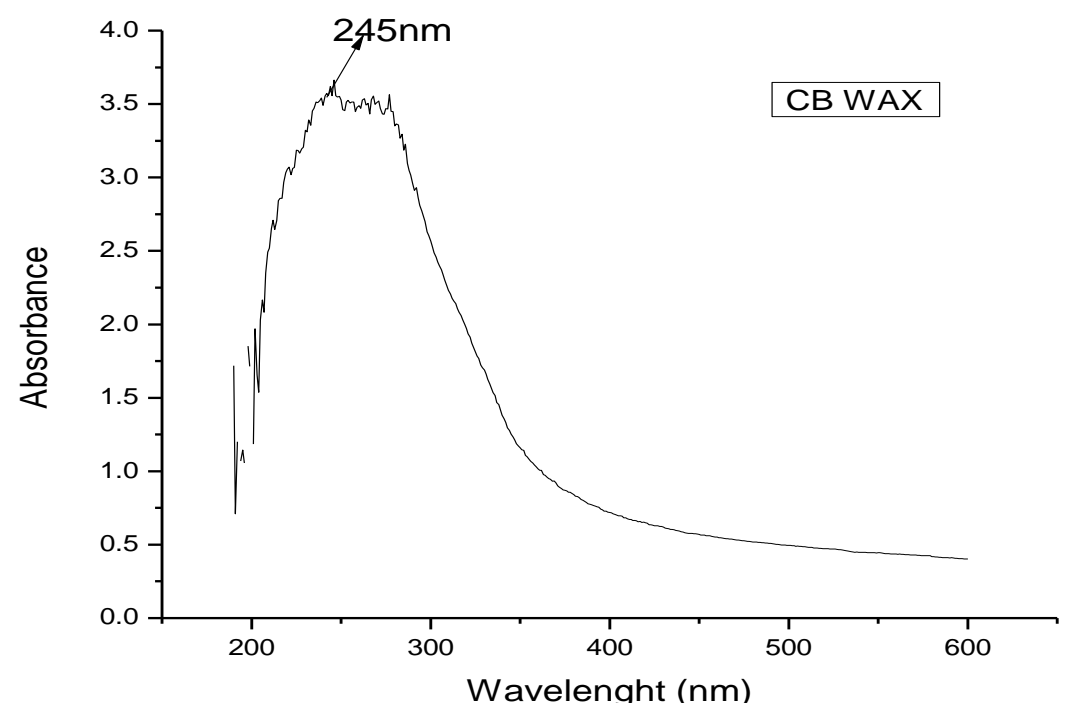

Figure 2: UV-Vis spectra of crude wax from cassava bagasse.

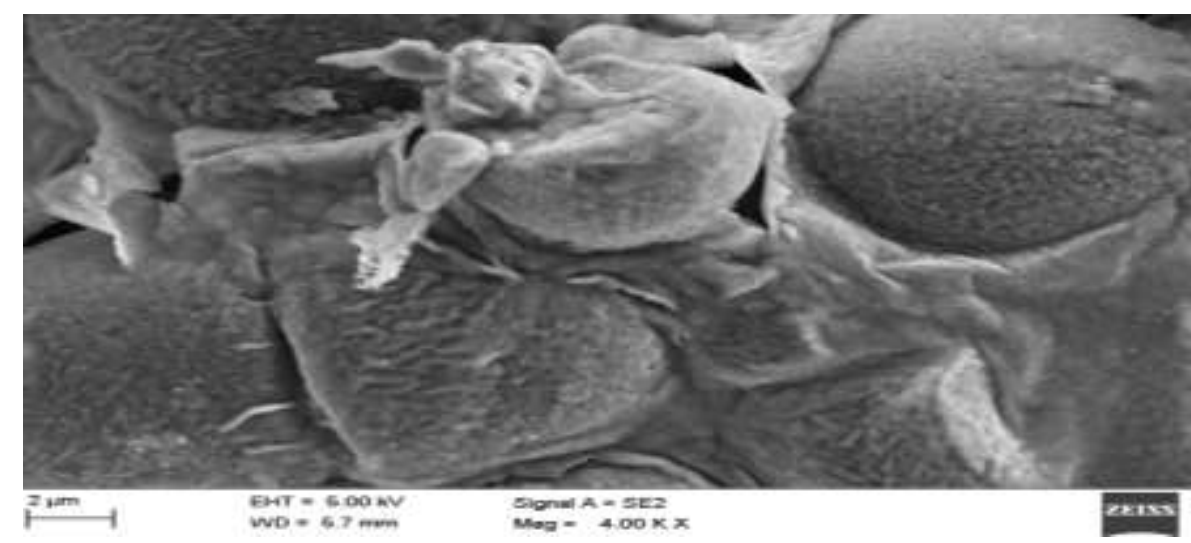

(3a)

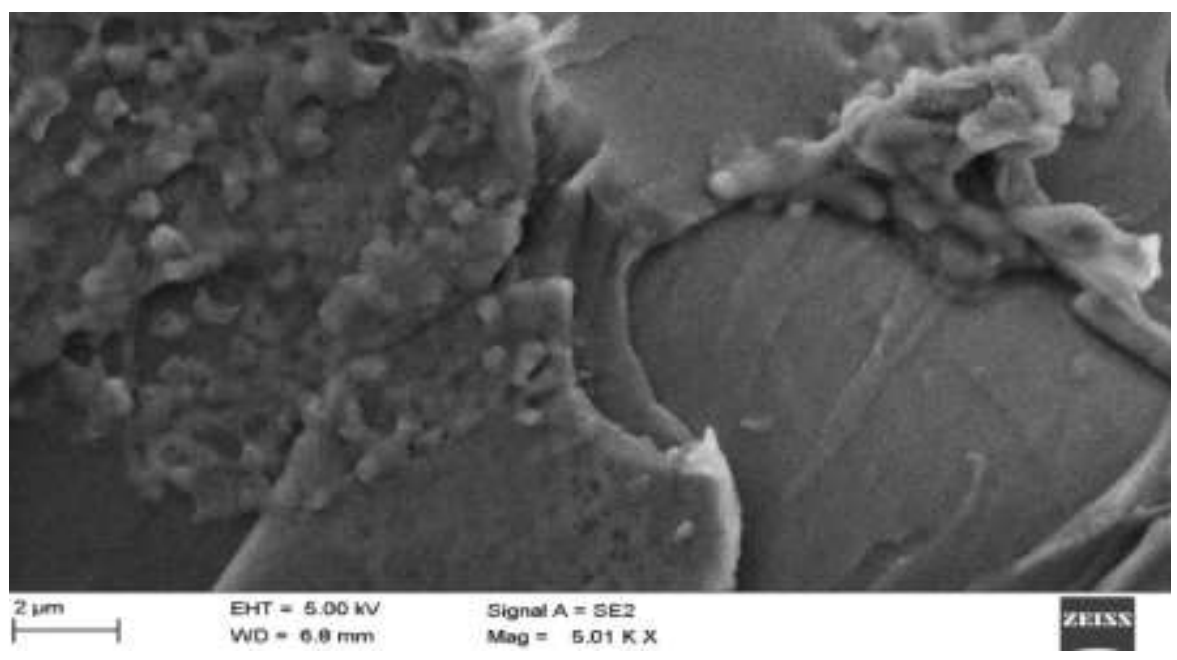

(3b)

Figure 3: (a) SEM micrograph of raw cassava bagasse (b) SEM micrograph of dewaxed cassava bagasse 


\section{CONCLUSION}

The present study showed a yield of $9.86 \%(\mathrm{w} / \mathrm{w})$ of crude cassava wax obtained from cassava bagasse using the mixture of benzene and methanol (mass ratio of 2:1) as the extraction reagent. The fouriertransform infrared spectroscopy showed prominent peaks at $2911 \mathrm{~cm}^{-1}(\mathrm{CH}), 1464 \mathrm{~cm}^{-1}\left(\mathrm{CH}_{2}\right), 1028 \mathrm{~cm}^{-}$ ${ }^{1}(-\mathrm{C}-\mathrm{O}), 1717 \mathrm{~cm}^{-1}(-\mathrm{CHO})$ and $3382 \mathrm{~cm}^{-1}(-\mathrm{OH})$ indicating the presence of alkanes, ketones, aldehyde and alcohol respectively. The ultraviolet qualitative analysis revealed that the wax absorbed UV light at $245 \mathrm{~nm}$ indicating the presence of conjugated dienes for cassava bagasse wax. In addition, the physicochemical properties of the wax which includes; melting point, saponification value, acid value, ester value and iodine value were $62.5^{\circ} \mathrm{C}$ and $275,29.15,245.85,14.66$ and $22.54 \mathrm{mg} / \mathrm{KOH} / \mathrm{g}$, respectively. Thus, cassava bagasse wax has potential for various industrial applications in food, pharmaceutical, cosmetics, medicine and several biological importance.

\section{ACKNOWLEDGMENTS}

The authors sincerely appreciate the financial contributions of TETFUND (Nigeria), through The Federal Polytechnic Ilaro and NRF/RISA (South Africa) and the support of Environmental and Nano Science Group, Chemistry Department, University of the Western Cape, Cape Town, South Africa for providing the laboratory space for our research.

\section{REFERENCES}

1. S. Widiarto, S. D. Yuwono, A. Rochliadi, I. M. Arcana. Preparation and characterization of cellulose and nanocellulose from agro-industrial waste - cassava peel. IOP Conference Series Material Science and Engineering, 2017, 176, 1-6.

2. FAO. Dimensions of Need: An atlas of food and agriculture. 1995.

3. S. O. Aro, V. A., Aletor, O. O. Tewe, J. O. Agbede. Nutritional potentials of cassava tuber wastes: A case study of a cassava starch processing factory in south-western Nigeria. Livestock. Research for Rural Development, 2010, 22 (11), 1-11.

4. K. M. Srinivasan, K. Chaudhari, S. S. Lele. Ash gourd peel wax: extraction, characterisation, and application as an edible coat for fruits, Food Science and Biotechnology, 2011, 20 (2), 383387.

5. K. Anuj, S. N. Yuvraj, C. Veena, K. B. Nishi. Characterisation of cellulose nanocrystals produced by acid-hydrolysis from sugarcane bagasse as agro-waste. Journal of Materials Physics and Chemistry, 2013, 2 (1), 1-8.

6. T. Bekele, B. Desalegn, E. Mitiku. Analysis of physico-chemical properties of beeswax produced in Bale natural forest, South-Eastern Ethiopia, European Journal of Biophysics. Special Issue: Environmental Toxicology, 2015, 4 (5), 42-46.

7. C. V. Abiaziem, I. A. Ojelade. Cassava peel wax: its extraction and characterization. Journal of Chemical, Biological and Physical Sciences, 2019, 9(4), 316-322. DOI: 10.24214/jcbps.A.9.4.31622.

8. B. Mangesh, S. S. Lele. Extraction and characterisation of sugarcane peel wax. International Scholarly Research Network ISRN Agronomy, 2012, 1-6. Article ID 340158. doi:10.5402/2012/340158. 
9. Q. Gaoxiang, P. Fen, X. Lian, L. Xiaoqing, H. Chao, L. Hailong, C. Xuefang, C. Xinde. Extraction and characterization of wax from sugarcane bagasse and the enzymatic hydrolysis of dewaxed sugarcane bagasse. Preparative Biochemistry and Biotechnology, 2017, 47 (3): 276-281. DOI: 10.1080/10826068.2016.1224246.

10. Y. Athukorala, G. Mazza, B. D. Oomah. Extraction, purification and characterisation of wax from flax (Linum usitatissimum) straw. European Journal of Lipid Science and Technology, 2009, 111 (7), 705-714.

11. A. Adewuyi, P. F. Vargas. Chemical modification of cellulose isolated from underutilized Hibiscus sabdariffa via surface grafting: A potential bio-based resource for industrial application. Kem. Ind., 2017, 66 (7-8), 327-338.

\section{* Corresponding Author: Abiaziem Chioma V. .}

Department of Science Laboratory Technology, the Federal Polytechnic

Ilaro, P.M.B. 50, Ogun State, Nigeria.

Date of publication on line 16.12.2019 